\title{
ANONIM ŞİRKET HUKUKUNDA RÜÇHAN HAKKININ SINIRLANDIRILMASI VE KALDIRILMASINDA HAKLI SEBEP ŞARTI
}

Ayhan BAKIR*

$\ddot{O} Z$

Anonim şirkette sermaye artırımı ile mevcut pay sahiplerinin şirketteki durumunun korunması amacıyla rüçhan hakkı tanınmıştır. Ancak haklı sebeplerin varlığı halinde pay sahiplerine tanınan rüçhan hakkının sınırlandırılması veya kaldırılması söz konusu olabilir.

Haklu sebep, somut olaya göre değişiklik göstermektedir. Bu nedenle öğretide üzerinde uzlaşılmış bir haklı sebebin tanımı bulunmamaktadır. Haklı sebep konusunda gösterilen sebeplerin haklı olup olmamast ile ilgili bazı kriterler ise ögretide kabul edilmektedir. Bahsedilen kriterler; anonim şirketin menfaati, sosyal gerekçeler ve ekonomik stratejisidir.

Haklı sebep konusunda Türk mevzuatında bir tanım yapılmamış olmakla birlikte birtakım örnekler verilmiştir. Bunlardan bazıları; halka arz, işletmelerin, işletme kısımlarının, iştiraklerin devralınması ve işçilerin şirkete katılmalarıdır.

Anonim şirkette rüçhan hakkının sınırlandırılması ve kaldırılması için şart olan haklı sebebin dürüstlük kuralı haricinde üç önemli sınırı bulunmaktadır. Bu sınırlar; eşitlik ilkesi, alınan kararın gerekli ve orantılı olmasıdır.

Anahtar Kelimeler: Anonim şirket, rüçhan hakkl, haklı sebep, sınırlandırma, kaldırma.

\section{FAIR CAUSE FOR LIMITATINON AND ABROGATION OF SUBSCRIPTION RIGHT IN JOINT-STOCK COMPANY LAW}

\section{ABSTRACT}

With the capital increase in the joint stock company, the subscription right has been granted to protect the status of the current shareholders in the company. However, in the presence of just cause, the subscription right granted to the shareholders may be limitation or abrogation.

\footnotetext{
* Arş. Gör. Dr, Ondokuz Mayıs Üniversitesi Ali Fuad Başgil Hukuk Fakültesi Ticaret Hukuku Anabilim Dalı / SAMSUN e-posta: aayhnbkr@gmail.com

ORCID: 0000-0001-5755-3333

DOI : : 10.34246/ahbvuhfd.1018664

Yayın Kuruluna Ulaştığı Tarih : $12 / 11 / 2020$

Yayınlanmasının Uygun Görüldüğü Tarih: 15/09/2021
} 
The just cause varies according to the concrete event. Therefore, there is no definition of a justified reason agreed upon in the doctrine. Some criteria about whether the reasons given for the just cause are just or not are accepted in the doctrine. The mentioned criteria; The interest of the joint stock company is social reasons and economic strategy.

Although there is no definition of just cause in Turkish legislation, some examples are given. Some of those; public offering is the takeover of businesses, business parts, subsidiaries and the participation of workers in the company.

There are three important limits to the rightful reason, which is a prerequisite for the limitation and abrogation of the subscription right in a joint stock company, except for the integrity rule. These limits are; The principle of equality is that the decision taken is necessary and proportionate.

Keywords: Joint-stock company, subscription right, fair cause, limitation, abrogation.

\section{Genel Olarak}

Anonim şirketlerde rüçhan (yeni pay alma) hakk1 ${ }^{1}$ (Bezugsrecht), diş kaynaklardan yapılan sermayenin artırımı neticesinde ortaya çıkan yeni payların $^{2}$ mevcut pay sahipleri ${ }^{3}$ tarafından öncelikle alınması hakkıdır ${ }^{4}$. Payın

1 Rüçhan hakkı terimi yerine Yargıtay'ın "artırılan sermayeye katılmada öncelik hakkı" ifadesi için bkz. Y. 11.HD., T. 28.10.2004, E. 2003/13782, K. 2004/10454.

2 Akünal, rüçhan hakkının söz konusu olması için sermaye artırımı neticesinde ortaya yeni pay senetlerinin çıkmasının şart olduğunu ileri sürmektedir (Teoman Akünal, "Anonim Ortaklıkta Pay Sahiplerinin Yeni Pay Alma Hakk1", 1969, 3(5), Mukayeseli Hukuk Araştırmaları Dergisi, s. 268). Biz bu görüşe katılmamaktayız. Zira sermaye artırımı neticesinde ortaya pay çıkması yeterli olup bunun ayrıca bir pay senedine bağlanması şart değildir. Nitekim çıplak payların aslen ve payların serbestçe devredilebilirliği ilkesi gereği devren iktisabı mümkündür. Ayrıca eğer sermaye artırım kararıyla ortaya çıkan paylar, bir senede bağlanmışsa rüçhan hakkının kullanımı neticesinde bunun iktisabı söz konusu olacaktır. Aynı görüşte bkz. Oruç Hami Şener, Teorik ve Uygulamalı Ortaklıklar Hukuku, 3. Bask1, Seçkin Yayınc1lık, 2017, s. 585 vd.

3 Şirketin kendi payını doğrudan iktisabı halinde bunun rüçhan hakkına sahip olmayacağ ancak bu iktisabın dolaylı (başka bir kişi aracılığıyla) olarak yapılması halinde bahsedilen hakkın kullanılabileceği yönünde bkz. Jens Koch/ Uwe Huffer, Aktiengesetz, 14. Auflage, CH Beck Verlag, 2020, AktG § 186, Rn. 9.

4 Mehmet Bahtiyar, Anonim Ortaklıkta Kayıtlı Sermaye Sistemi ve Sermaye Artırımı, Beta Basım, 1996, s. 158; Şener, s. 585; Esra Cenkci, "Kayıtlı Sermaye Sisteminde Yeni Pay Alma (Rüçhan) Hakkının Sınırlandırılması Bağlamında Genel Kurulun Yetkileri -Alman 
aslen kazanımı imkânı veren bu hak, pay sahiplerinin paylarının nispeti ile orantilidir ${ }^{5}$.

Anonim şirket hukukunda rüçhan hakkının doğumu için genel kurulun sermaye artırım kararı alması gerekir6 ${ }^{6}$. Ancak genel kurulun bu yönde bir karar alması rüçhan hakkının mutlaka uygulanacağı anlamına gelmemektedir. Zira haklı sebeplerin varlığ 1 halinde söz konusu hakkın sınırlandırılması veya

ve İsviçre Hukuku ile Karş1laştırmalı”, 2016, 122, Türkiye Barolar Birliği Dergisi, s. 316; Fatih Bilgili/ Ertan Demirkap1, Șirketler Hukuku, 3. Bask1, Dora, 2013, s. 525. Doktrindeki rüçhan hakkı tanımları için ayrıca bkz. Şükrü Yıldız, Anonim Ortaklıkta Yeni Pay Alma Hakk1, Beta Basim, 1996, s. 77 vd.

5 Edward E. Ott, Das Bezugsrecht der Aktionäre, Diss., 1962, s. 12; Akünal, s. 257; Philipp Schaller /Martin A. Kessler, Aktienrecht Kommentar Aktiengesellschaft, Rechnungslegungsrecht, VegüV, GeBüV, VASR(Hrsg. Jeannette K. Wimbmer)-Zürich, 2016, OR Art. 652b, Nr. 1; Can Yaşar Göksoy, "Anonim Ortaklıkta Pay Sahibinin Yeni Pay Alma Hakkının Kaldırılması”, 2003, Bilgi Toplumunda Hukuk, Ünal Tekinalp'e Armağan, s. 363; Zühtü Aytaç, “Anonim Ortaklıklarda Rüçhan Hakkı”, Ticaret Hukuku ve Yargıtay Kararları Sempozyumu II, 1985, s. 297; Conradin Cramer, Allgemeine Bestimmungen, Art. 620-659b OR Die Aktiengesellschaft (Hrsg. Lukas Handschin), 2. Auflage, Schulthess, 2016, OR Art. 652b, NR. 1; Yusuf Murat Akın, "Kayıtlı Sermayede Rüçhan Hakkının Sınırlandırılması veya İlgilinin Bu Hakk1 Kullanımdan Yoksun Bırakılmasındaki Kıstaslar”, 1995, Prof. Dr. Reha Poroy'a Armağan, IÜHF, s. 13; Necat, Azarkan, Die Kapitalerhöhung in der AG nach deutschem und türkischem Recht, Dis., Peter Lang, 2008, s. 92; Claude Lambert/ Gericke Dieter, OR Kommentar Schweizerisches Obligationenrecht (Hrsg. Kostkiewicz Jolanta Kren / Stephan Wolf / Marc Amstutz/ Roland Fankhauser), 3. Auflage, Orell Füssli Verlag, 2016, OR Art. 652b, Nr. 2; Wolfgang Müller, Personengesellschaften und Aktiengesellschaft Art. 530-771 OR (Hrsg. Vito Roberto/ Hans Rudolf Trueb), 2. Auflage, Schulthess, 2012, OR Art. 652b, Nr. 1; Ramon Bühler, Kapitalerhöhung aus Eigenkapital nach Art. 652d OR, Dis., Universität St. Gallen, 2019, s. 117; Wolfgang Servatius, Kommentar zum Aktiengesetz (Hrsg. Gerald Spindler/ Eberhard Stilz), Bd. 2, 4. Auflage, 2019, AktG § 186, Rn. 11; Marc Hermanns, Gesellschaftsrecht (Hrsg. Martin Henssler/ Lutz Strohn), 4. Auflage, 2019, AktG $\S$ 186, Rn. 1; Cenkci, s. 316; Şener, s. 585; Mirko Sickinger/ Thorsten Küthe, Münchener Anwaltshandbuch Aktienrecht (Hrsg. Matthias Schuppen/ Bernhard Schaub), 3. Auflage, CH Beck Verlag, 2018, Mah AktR § 33, Rn. 39; 11. HD., T. 22.9.2016, E. 2015/15396, K. 2016/7426 (http://www.kazanci.com/kho2/ibb/files/11hd-2015-15396.htm, Erişim Tarihi: 9.11.2020).

6 Göksoy, s. 363. İç kaynaklardan yapılan sermaye artırımında da pay sahiplerinin rüçhan hakkına sahip olduğu hakkında bkz. Şükrü Yıldız, Anonim Ortaklıkta Pay Sahipleri Açısından Eşit İşlem İlkesi, Seçkin Yayıncılık, 2004, s. 156 vd. (anılış: Yıldız, Eşit İşlem); Akın, s. 17. Aytaç ise haklı olarak iç kaynaklardan yapılan sermaye artırımında rüçhan hakkının söz konusu olmadığı fikrindedir. Aytaç'a göre, iç kaynaklardan yapılan sermaye artırımında bedelsiz pay edinme hakkı, müktesep hak niteliğinde olduğundan esas sözleşme hükmüyle ya da genel kurul kararıyla bunun sinırlandırılması veya kaldırılması mümkün değildir (Aytaç, s. 331, dip.74). Şartlı sermaye artırımında rüçhan hakkının söz konusu olmadığg yönünde bkz. Gabriele Apfelbacher/ Gerold Niggemann, Aktiengesetz Kommentar (Hrsg. Wolfgang Holters), 3. Auflage, CH Beck Verlag, 2017, AktG § 186, Rn. 73. 
kaldırılması mümkündür ${ }^{7}$. Bunun için usul ve esasa dair birtakım şartların mevcudiyeti şarttır ${ }^{8}$.

Rüçhan hakkının sınırlandırılması, pay sahiplerinin sermaye artırımı kararı neticesinde ortaya çıkan paylardan öncelikle alma haklarının kısmen kullanılamamasıdır. Bu sınırlandırma, pay sahiplerinin alabileceği tüm paylardan bir kısmının veya birden çok kategoride çıkarılan paylardan sadece bazılarının alınamaması şeklinde de tesis edilebilir. Ayrıca pay sahiplerinin rüçhan hakkını devredememesi şeklinde de bunun sınırlandırılması da söz konusu olabilir. Rüçhan hakkının kaldırılması ise mevcut pay sahiplerinin sermaye artırımı neticesinde ortaya çıkan payları öncelikle almalarının tamamen yasaklanmasidir ${ }^{10}$.

Anonim şirket hukukunda rüçhan hakkının kabul edilmesinin önemli gerekçeleri vardır ${ }^{11}$. Bunlardan en önemlisi; rüçhan hakkının kabulü ile mevcut pay sahiplerinin sermaye artırımı sonrasında anonim şirketteki pay oranının korunması amacıdır ${ }^{12}$. Zira çoğunluk veya yönetim kurulunun gereksiz sermaye artırımına gitmesi halinde diğer pay sahiplerinin menfaatinin tehlikeye uğramaması adına bir tedbir olarak rüçhan hakkının kullanılması mümkündür. $\mathrm{Bu}$ durum, aynı zamanda şirket menfaatinin korunmasına da hizmet etmektedir ${ }^{13}$.

7 Schaller/ Kessler, OR Art. 652b, Nr. 2.

8 Apfelbacher/ Niggemann/ Holters, AktG § 186, Rn. 39.

9 Göksoy, s. 367; Jan Schurnbrand, Münchener Kommentar zum AktG (Hrsg. Wulf Goette/ Mathias Habersack/ Susanne Kalss), Bd. 4, 4. Auflage, CH Beck Verlag, 2018, AktG § 186, Rn. 141.

10 Burak Adıgüzel, “Anonim Şirketlerde Rüçhan Hakkının Sınırlanması veya Kaldırılması”, 2014, 18(1), Gazi Üniversitesi Hukuk Fakültesi Dergisi, s. 3.

11 Bu konu hakkında bkz. Kristoffel Grechenig, Bezugsrechtsausschluss und Ausgabepreis nach Art. 652b OR, Schweizerische Zeitschrift für Wirtschafts- und Finanzmarktrecht, SZW, Schulthess, 2008, s. 490 vd.; Y1ldız, s. 111 vd.; Koch/ Hüffer, AktG § 186, Rn. 2.

12 Schaller/ Kessler, OR Art. 652b, Nr. 2; Hasan Pulaşl1, Şirketler Hukuku Genel Esaslar, 4. Bask1, Adalet Yayınevi, 2016, § 25 Nr. 35; Lambert/ Dieter, OR Art. 652b, Nr. 1; Cramer, OR Art. 652b, Nr. 3; Şükrü Yıldız, "6102 sayılı Türk Ticaret Kanunu'nda Rüçhan Hakk1 Konusunda Getirilen Değişiklikler”, 2012, 18(2), 6102 Sayılı Türk Ticaret Kanunu'nu Beklerken Sempozyumu, Marmara Üniversitesi Hukuk Fakültesi Hukuk Araştırmaları Dergisi, Özel Sayı, s. 809 (anılış: Yıldız, Değişiklikler); Azarkan, s. 92; Schürnbrand/ Goette/ Habersack/ Kalss, AktG $§ 186$, Rn. 2; Şener, s. 586. Bu konu hakkında bkz. TTK m. 461 gerekçe; Akünal, s. 266 vd.; Koch/ Hüffer, AktG § 186, Rn. 2; Göksoy, s. 364 vd.; Bühler, s. 115.

13 Grechenig, s. 490; Yıldız, s. 84; Markus S. Rieder/ Daniel Holzmann, Aktiengesetz Kommentar (Hrsg. Hans Christoph Grigoleit), CH Beck Verlag, 2013, AktG § 186, Rn. 1. 
Rüçhan hakkının sınırlandırılması ve kaldırılması için "haklı sebebin" şart olması 6102 sayılı Türk Ticaret Kanunu (TTK) m. 461/2'de açıkça belirtilmiştir ${ }^{14}$. Dolayısıyla pay sahipliği konumunun korunması adına hayati öneme sahip rüçhan hakkı konusunda haklı sebep şartı da en az bu kadar önemlidir. Bu nedenle söz edilen şartın incelenmesi gerekir ${ }^{15}$.

\section{Haklı Sebep Terimi}

Rüçhan hakkı için oldukça önemli olan haklı sebep (wichtige Gründe) kavramı, alışıldığı üzere TTK'da tanımlanmamıştır. Keza ilgili maddenin gerekçesinde de haklı sebep kavramı açıklanmamıştır. Bu konuda sadece TTK m. 461/2'de hangi hallerin haklı sebep sayılabileceği örnek kabilinden belirtilmiştir. Daha açık bir şekilde ifade etmek gerekirse; TTK m. 461/2'de haklı sebep için gösterilen haller tahdidi (numerus clausus) değil, tadadi niteliktedir ${ }^{16}$.

Anonim şirket menfaati, sosyal ya da ekonomik gerekçelerle; dürüstlük kuralına, gereklilik, orantılılık ve eşit işlem ilkesine uygun olarak rüçhan hakkının sınırlandırılmasını ya da kaldırılmasını haklı kılan objektif nedenlere kanaatimizce haklı sebep denir.

Rüçhan hakkının sınırlandırılması veya kaldırılması için gösterilen sebebin haklı olup olmadığı hâkimin takdirindedir. Hâkim, 4721 sayılı Türk Medeni Kanunu (TMK) m. 4 gereğince hukuka ve hakkaniyete göre karar verir ${ }^{17}$.

Haklı sebebin olup olmadığı, somut olaya göre özellikle incelenmelidir ${ }^{18}$. Başka bir ifadeyle rüçhan hakkının sınırlandırılması ve kaldırılması için elzem olan haklı sebep somut olayın niteliklerine göre belirlenmelidir ${ }^{19}$. Ancak haklı sebebin vaka bazında "objektif olarak gerekçelendirilmesi"

\footnotetext{
14 RG, T. 14.02.2011, S. 27846.

15 Önemle belirtmek gerekirse; esas sözleşme ile rüçhan hakkının sınırlandırılması ve kaldırılması mümkün değildir. Bu işlem, yalnızca genel kurul veya yönetim kurulu kararıyla yapılabilir (Schürnbrand/ Goette/ Habersack/ Kalss, AktG § 186, Rn. 19; Rieder/ Holzmann/ Grigoleit, AktG § 186, Rn. 45).

16 TTK m. 461/2 gerekçe.

17 RG, T. 8.12.2001, S. 24607.

18 Wolfgang Müller, Personengesellschaften und Aktiengesellschaft Art. 530-771 OR (Hrsg. Vito Roberto/ Hans Rudolf Trueb), 2. Auflage, Schulthess, 2012, OR Art. 652b, Nr. 13; Grechenig, s. 491.

19 TTK m. 461/2 gerekçe.
} 
gerekir ${ }^{20}$. Aksi takdirde gösterilen sebep, "haklı" sayılmayacaktır. Rüçhan hakkının sınırlandırılması ve kaldırılması için gösterilen sebebin haklı olması için bu, şirket ve/veya pay sahipleri açısından korunmaya değer olmalıdır. Bu bağlamda özellikle şirketin amacı ve orta ya da uzun vadeli sürdürülebilir gelişimine yönelik sebepler korunmaya değerdir. Dolayısıyla haklı sebep, şirket ve pay sahipleri için objektif açıdan korunmaya değer menfaatlerdir ${ }^{21}$.

Rüçhan hakkının sınırlandırılması ve kaldırılması için gösterilen sebebin sadece şirket içindeki ya da dişındaki belirli kişi ya da grupların menfaatine hizmet etmesi, "haklı" görülmemektedir ${ }^{22}$. Dolayısıyla rüçhan hakkının sınırlandırılması ve kaldırılması kararı için yeterli olan güç, her sebebi "haklılık" kisvesi altında sunamayacaktır ${ }^{23}$. Örneğin pay sahiplerinin rüçhan hakkını kullanıp kullanmayacağı konusundaki belirsizlik, bunun sınırlandırılması ya da kaldırılması için haklı sebep teşkil etmeyecektir ${ }^{24}$. Benzer şekilde rüçhan hakkı kaldırılan pay sahibinin genel kurulda olmaması, sermaye artırımı kararında olumlu yönde oy kullanmamış olması de haklı sebep sayılmamaktadir ${ }^{25}$.

Rüçhan hakkının sınırlandırılması ve kaldırılması için haklı sebep şartının öngörülmesinin iki önemli kuşatıcı etkisi olduğu düşünülmektedir. Bunlardan birincisi, ayrımcılığın açıkça yasaklanmasıdır. İkincisi ise şirketler hukukunun temel ilkelerine uyumdur. Bunlardan dolayı rüçhan hakkının sınırlandırılması ve kaldırılması için (örneğin eşit işlem konusunda) haklı sebebin "objektif olarak açıklanması" zorunluluğu doğmuştur ${ }^{26}$.

20 Koch/ Hüffer, AktG § 186, Rn. 25; Sickinger/ Küthe/ Schuppen/ Schaub, Mah AktR § 33 Rn. 99; Schürnbrand/ Goette/ Habersack/ Kalss, AktG § 186, Rn. 103; Cramer, OR Art. 652b, Nr. 21; Rieder/ Holzmann/ Grigoleit, AktG $\S 186$, Rn. 52. Alman ve Avusturya hukukuna göre tüm pay sahiplerinin rızası varsa rüçhan hakkının sınırlandırılması ve kaldırılması gerekçelerinin açıklanması gerekmez (Apfelbacher/ Niggemann/ Holters, AktG § 186, Rn. 60; Schürnbrand/ Goette/ Habersack/ Kalss, AktG § 186, Rn. 207; Koch/ Hüffer, AktG § 186, Rn. 25; Sickinger/ Küthe/ Schuppen/ Schaub, Mah AktR § 33 Rn. 99).

21 Cramer, OR Art. 652b, Nr. 24.

22 Güzin Üçışık/ Aydın Çelik, Anonim Ortaklıklar Hukuku, C. I, Adalet Yayınevi, 2013, s. 428.

23 Cramer, OR Art. 652b, Nr. 25.

24 Servatius/ Spindler/ Stilz, AktG § 186, Rn. 45.

2511 HD., T. 22.9.2016, E. 2015/15396, K. 2016/7426 (http://www.kazanci.com/kho2/ibb/ files/11hd-2015-15396.htm, Erişim Tarihi: 9.11.2020).

26 Bühler, s. 117. 


\section{Gösterilen Sebeplerin Haklı Olması}

\section{A. Anonim Şirketin Menfaati}

Rüçhan hakkının sınırlandırılması ve kaldırılmasında anonim şirket menfaatleri gerekçe olarak gösterilebilir ${ }^{27}$. Bu anlamda şirketin pay sahiplerinden bağımsız ayrı bir varlığı olması ve bunun menfaatinin daha üstün görülmesi nedeniyle rüçhan hakkı sınırlandırılıp kaldırılabilir. Dolayısıyla rüçhan hakkının sınırlandırılması ve kaldırılması konusunda "anonim şirket menfaatinin pay sahiplerinin şahsi menfaatinden daha üstün ve ayrıcalıklı olması" kabul görmektedir ${ }^{28}$. Bu husus, şirket menfaatinin önceliği ilkesinden ç1karılabilmektedir. Bu ilke gereğince pay sahiplerinin menfaatine nazaran, şirketin menfaati önceliklidir ${ }^{29}$. Keza aynı husus, yönetim kurulu üyelerinin sadakat yükümlülüğ̈ünden de anlaşılmaktadır. Zira yönetim kurulu üyeleri, şirket ile pay sahiplerinin (veya diğer kimselerin) menfaatlerinin çatışması halinde şirketi tercih etmek zorundadir ${ }^{30}$.

Anonim şirketin menfaati gerekçesiyle rüçhan hakkının sınırlandırılabilmesi veya kaldırılabilmesi için bu seçeneğin tek veya en iyi seçenek olması şarttır ${ }^{31}$. Söz konusu menfaat, başka seçeneklerle de elde edilebilecekse ya da bundan daha iyi bir yol mevcutsa öncelikle bunlara başvurulmalıdır. Zira rüçhan hakkı, anonim şirket hukukunda sermaye artırımında pay sahiplerini koruyan temel haklardan biri olduğundan mümkün olduğunca bunun kısıtlanmaması gerekir ${ }^{32}$.

Rüçhan hakkının sinırlandırılması ve kaldırılmasında yapılan değerlendirmede şirket menfaati son derece önemlidir. Öyle ki rüçhan hakkına

27 Böckli, Nr. 254; Hermanns/ Henssler/ Strohn, AktG § 186, Rn. 12; Apfelbacher/ Niggemann/ Holters, AktG § 186, Rn. 62; Schürnbrand/ Goette/ Habersack/ Kalss, AktG § 186, Rn. 98; Rieder/ Holzmann/ Grigoleit, AktG § 186, Rn. 53; Göksoy, s. 397; Cramer, OR Art. 652b, Nr. 21; Servatius/ Spindler/ Stilz, AktG § 186, Rn. 43-44; Koch/ Hüffer, AktG § 186, Rn. 26; Sickinger/ Küthe/ Schuppen/ Schaub, Mah AktR § 33 Rn. 101.

28 Krämer, s. 33; Y1ldiz, s. 287; Apfelbacher/ Niggemann/ Holters, AktG § 186, Rn. 64; Adıgüzel, s. 6.

${ }_{29} \mathrm{Bu}$ ilkenin doktrinde "Unternehmen an sich" teorisi olarak da adlandırıldığı hakkında bkz. Krämer, s. 33 vd.; Ömer Korkut, "Anonim Şirketlerde Şirket Menfaati Kavramının Somutlaştırılması”, 2007, 11(2), Çukurova Üniversitesi İktisadi ve İdari Bilimler Dergisi, s. 3 .

$30 \quad$ Korkut, s. 3; Y1ldiz, s. 287.

31 Hermanns/ Henssler/ Strohn, AktG § 186, Rn. 12.

32 Apfelbacher/ Niggemann/ Holters, AktG § 186, Rn. 60. 
yapılacak kısitlama ne kadar ciddi olursa, bu konudaki şirket menfaati de o derece önemli olmalıdır ${ }^{33}$. Dolayısıyla rüçhan hakkının kaldırılması için gösterilen şirket menfaatinin, bunun sınırlandırılması konusundaki şirket menfaatinden daha önemli olması gerekir.

Anonim şirketin menfaatinin pay sahiplerinin menfaatlerinden üstün görülmesi; pay sahiplerinin korunması, şirket malvarlığının korunması ile ilgili kurallar çerçevesinde titizlikle incelenmesi gereken bir konudur. Aksi takdirde genel kurul kararının kısmen ya da tamamen iptal edilip rüçhan hakk1 konusundaki kısıtlamaların uygulanmaması söz konusu olabilir ${ }^{34}$. Sonuç olarak, somut olayda şirket menfaatinin gerekçe gösterilip rüçhan hakkının sınırlandırılması ve kaldırılması kolay değildir. Dolayısıyla şirketin menfaati olarak gösterilen gerekçelerin haklı olup olmadığı her bir somut olay bakımından dikkatlice değerlendirilmesi gereken bir konudur. $\mathrm{Bu}$ anlamda anonim şirket menfaatini somutlaştırmak için birtakım kriterler olduğu doktrinde düşünülmektedir. Bu kriterler; anonim şirketin amacı ve konusu, değerinin artırılması, pay sahiplerinin menfaati, farklı çıkar gruplarının değerlendirilmesidir ${ }^{35}$.

Anonim şirket menfaatinin belirlenmesinde ilk kriter, şirketin amac1 ve konusudur. Anonim şirketler, iktisadi bir amaç için kurulmaktadır. Bunu gerçekleştirmek için ise hukuka uygun olan her alanda faaliyet gösterebilir. Bu faaliyet konularının TTK m. 339/2-b gereğince esas sözleşmede belirtilmesi şartır. Dolayısıyla rüçhan hakkının sınırlandırılması veya kaldırılması incelenirken esas sözleşmedeki şirketin amaç ve konusundan yararlanılabilir ${ }^{36}$. Ancak böyle bir incelemede şirketin amaç ve konu kriteri tek başına yetersiz kalabilir $^{37}$. Bu anlamda diğer kriterlerden faydalanılabiliir ${ }^{38}$.

Rüçhan hakkının sınırlandırılması ve kaldırılmasında anonim şirket menfaatinin olup olmadığı yönündeki incelemede, şirket değerinin artırılmas1

33 Koch/ Hüffer, AktG § 186, Rn. 28; Rieder/ Holzmann/ Grigoleit, AktG § 186, Rn. 54.

34 Nitekim TTK m. 357'nin gerekçesinde hukuka aykırı olan rüçhan hakkının sınırlandırılması ve kaldırılmasının iptal edileceği belirtilmiştir. Bu konu hakkında ayrıca bkz. Y. 11.HD., T. 28.10.2004, E. 2003/13782, K. 2004/10454.

35 Bu konular hakkında ayrıntılı bilgi için bkz. Korkut, s. 4 vd.

36 Schürnbrand/ Goette/ Habersack/ Kalss, AktG § 186, Rn. 98.

37 Anonim şirket menfaatinin şirket amacıyla desteklenmesi halinde rüçhan hakkı konusundaki kısıtlamaların hukuka uygun sayılacağı hakkında bkz. Apfelbacher/ Niggemann/ Holters, AktG $\S 186$, Rn. 62.

38 Korkut, s. 5. 
ikinci kriterdir. Özellikle yönetim kurulu üyeleri için şirket kazancını en üst seviyeye çıkarma (Gewinnmaximierung) yükümlülüğü söz konusudur. $\mathrm{Bu}$ nedenle yönetim kurulu üyelerinin yaptığ 1 işlemler, şirketin kazanç sağlamas1 veya kazancın artmasına hizmet etmelidir. Yapılan her işlemin kısa ve uzun vadedeki etkileri dikkate alınmalıdır. Zira bu işlemlerin sadece kısa veya uzun vadedeki etkileri ele alındığında hata yapılıp şirket menfaatinin ihlali sonucuna varılabilir ${ }^{39}$. Örneğin banka yönetim kurulu üyesinin büyük bir spor kulübüne sponsor olup stadyum yapılmasına dair borç altına girdiği hukuki işlem, kısa vadede şirketin zararınadır. Ancak bu anlaşma uzun vadede bankanın menfaatine olabilir. Öte yandan bu işlem, mevcut pay sahiplerinin menfaatini ciddi anlamda tehdit edebilir. Dolayısıyla yönetim kurulu üyeleri tarafindan yapılan kısa ve uzun vadedeki işlemler, bir yandan şirketin yararına iken diğer yandan mevcut pay sahiplerinin zararına olabilir. Bunun için yapılan iş ve işlemlerin pay sahipleri değerine (shareholders value) uygun olması gerekir. Aksi takdirde şirket piyasa değerinin artması zordur. Özellikle halka açık anonim şirketler, bu ihlal sebebi ile büyük zarar görebilir. Sonuç olarak şirket değerini kısa ve uzun vadede artıran, spekülasyon amaçlı veya niteliği taşımayan iş ve işlemlerin yapılması şirketin menfaatinedir ${ }^{40}$. Kanaatimizce yönetim kurulu üyeleri tarafından yapılan işlemler söz konusu olduğundan bu kriter, rüçhan hakkının sınırlandırılması ve kaldırılması açısından sabit sermaye sistemine nazaran kayıtlı sermaye sisteminde daha çok öne çıkmaktadır ${ }^{41}$.

Rüçhan hakkının sınırlandırılması ve kaldırılmasında anonim şirket menfaatinin olup olmadığı yönündeki incelemede üçüncü kriter, pay sahiplerinin menfaatidir ${ }^{42}$. Yönetim kurulu üyelerince yapılan işlemlerde esas olarak şirket menfaati güdülse de bu, pay sahipleri menfaatinin tamamen göz ardı edileceği ya da yok sayılacağı anlamına gelmemektedir. Ancak şu da var ki şirket menfaatine olan işlemler mantıken pay sahiplerinin de lehinedir. Dolayısıyla her iki menfaatin birbirine paralel olduğu yönünde bir karine çıkarılabilmektedir. Ayrıca bazı durumlarda pay sahipleri menfaatinin gözetilmesi şirketin de lehine olabilmektedir. Örneğin tek pay sahibinin olduğu anonim şirketlerde veya şirketler topluluğunda özellikle tam hakimiyet halinde, pay sahiplerinin menfaatinin üstün tutulması ilgili

\footnotetext{
39 Korkut, s. 6.

40 Korkut, s. 6.

${ }^{41}$ Kayıtlı sermaye sisteminde rüçhan hakk1 konusunda bkz. Cenkci, s. 318 vd.

42 Schürnbrand/ Goette/ Habersack/ Kalss, AktG § 186, Rn. 102; Göksoy, s. 401.
} 
şirketin de menfaatinedir ${ }^{43}$. Şunu da eklemek gerekirse; rüçhan hakkının sınırlandırılması ve kaldırılmasının çoğunluk pay sahipleri lehine olması şüphe uyandırmaktadır ${ }^{44}$. Bu anlamda yapılan incelemede haklı sebep sınırları üzerinde durulmalıdır. Kanaatimizce yönetim kurulu üyeleri tarafından yapılan işlemler söz konusu olduğundan ikinci kriter gibi üçüncüsü de rüçhan hakkının sınırlandırılması ve kaldırılması açısından sabit sermaye sistemine nazaran kayıtlı sermaye sisteminde öne çıkmaktadır.

Rüçhan hakkının sınırlandırılması ve kaldırılmasında anonim şirket menfaatinin olup olmadığı yönündeki incelemede sonuncu kriter, farklı çıkar gruplarının değerlendirilmesidir. Bunun için menfaat analizi yapılıp her bir grubun "müşterek menfaatler" ya da "asgari müşterekleri" (Minimalkonsens) tespit edilmelidir. Buna uygun iş ve işlemler yapılması anonim şirketin menfaatine olacaktır ${ }^{45}$. Eksik bir değerlendirme ile sadece çoğunluk grubun menfaatlerinin dikkate alınıp asgari müşterekler aranmazsa rüçhan hakkının sınırlandırılması ve kaldırılması kararı iptal edilebilir ${ }^{46}$.

\section{B. Sosyal Gerekçeler}

Doktrinde anonim şirketin sosyal gerekçelerle rüçhan hakkını sınırlayıp kaldırabileceği ileri sürülmüştür ${ }^{47}$. Gerçekten de bazı kişilerin pay sahibi olması için sosyal gerekçeler ileri sürülüp rüçhan hakkının sınırlandırılması ve kaldırılması mümkündür. Örneğin şehit yakınlarının pay sahibi olması gerekçesiyle rüçhan hakkının sınırlandırılması veya kaldırılması mümkündür. Benzer şekilde anonim şirket, bağış yapmak yerine lösemi hastalarının menfaatlerini gözeten bir derneğin pay sahibi sıfatını kazanması için rüçhan hakkını sınırlandırabilir ya da kaldırabilir.

\section{Anonim Şirketin Ekonomik Stratejisi}

Anonim şirketin ekonomik stratejisi ileri sürülerek rüçhan hakkının sınırlandırılması ve kaldırılması mümkündür ${ }^{48}$. Gerçekten de liberal ve küresel ekonomide şirketlerin varlığını idame ettirmeleri veya büyüme stratejileri

\footnotetext{
43 Korkut, s. 7.

44 Apfelbacher/ Niggemann/ Holters, AktG § 186, Rn. 62.

45 Korkut, s. 7.

46 Schürnbrand/ Goette/ Habersack/ Kalss, AktG § 186, Rn. 99.

47 Adigüzel, s. 9.

48 Servatius/ Spindler/ Stilz, AktG § 186, Rn. 45.
} 
gereği bazı özel taktiklere başvurması kaçınılmazdır. Bu anlamda stratejik öneme sahip bazı özel kişilerin pay sahibi olması gerekebilir. İşte bu kimselerin pay sahibi sıfatını elde edebilmesi için rüçhan hakkının sınırlandırılması veya kaldırılması haklı görülebilir.

Anonim şirketin ekonomik stratejisi için en uygun ya da tek araç rüçhan hakkının sınırlandırılması veya kaldırılması olursa bu haklı sebep sayılacaktır ${ }^{49}$. Doktrinde anonim şirketin ekonomik stratejisi gereği payların sermaye piyasasında yüksek talep görebileceği gerekçesiyle rüçhan hakkının sınırlandırılması ve kaldırılmasının haklı sebebe dayanmayacağı ileri sürülmüştür ${ }^{50}$.

Anonim şirketin ekonomik stratejilerinden biri de devralma suretiyle birleşmedir. Şirket, bunu haklı sebep olarak gösterip rüçhan hakkını sınırlandırıp kaldırabilir. Nitekim TTK m. 142/1'den zımnen bu sonuç çıkarılabilmektedir. Buna göre; devrolunan şirketteki ortak veya pay sahipleri, devralan şirketten hakları nispetinde pay alacaktır. Bunun için de devralan şirketteki mevcut pay sahiplerinin rüçhan hakkının kaldırılması gerekir. Kanun koyucu böyle bir kısıtlamanın haklı sebeplerle yapıldığını örtülü olarak kabul etmektedir.

\section{Mevzuatımızda Gösterilen Haklı Sebep Örnekleri}

Anonim şirket hukukunda rüçhan hakkının sınırlandırılması ve kaldırılması için haklı sebep halleri, başta TTK olmak üzere muhtelif kanunlarda düzenlenmiştir. Keza doktrinde ve içtihatlarda da haklı sebep örnekleri verilmiştir. Bunlara geçmeden evvel önemle belirtmek gerekirse; mevzuattaki hallerin varlığı, her zaman rüçhan hakkının sınırlandırılması ve kaldırılmasını gerektirmemektedir. Bunların olması rüçhan hakkının sınırlandırılmasını ve kaldırılmasını zorunlu kılmamaktadır. Ayrıca rüçhan hakkının sınırlandırılması ve kaldırılması için her ne kadar, mevzuatta birer haklı sebep örneği olarak belirtilmişse de bunun daima hukuka uygun olduğu anlamına gelmemektedir. Özellikle aşağıda ele alınacak "haklı sebebin sınırlarına" ve TMK m. 2/1'deki dürüstlük kuralına aykırı olarak mevzuattaki haklı sebep hallerini kullanıp rüçhan hakkının sınırlandırılması ve kaldırılması hukuka aykırıdır. Başka bir ifadeyle haklı sebep sınırları ve TMK m. 2/1'e aykırı olarak rüçhan hakkının sınırlandırılmasına ve kaldırılmasına gerekçe olarak mevzuatımızdaki haklı sebep hallerinin gösterilmesi bu işlemi "haklı"

\footnotetext{
49 Servatius/ Spindler/ Stilz, AktG § 186, Rn. 47.

50 Servatius/ Spindler/ Stilz, AktG § 186, Rn. 45.
} 
kılmaya yetmeyecektir. Örneğin TTK m. 461/2'deki haklı sebep hallerinden biri olan halka arz için rüçhan hakkının sınırlandırılması ve kaldırılması, eşit işlem ilkesine aykırı olarak sadece bazı pay sahipleri için kabul edilmişse bu hukuka aykırı olacaktır.

Rüçhan hakkının sınırlandırılması ve kaldırılması hakkında TTK m. 461/2'de yer alan haklı sebep örnekleri; "halka arz, işletmelerin, işletme kısımlarının, iştiraklerin devralınması ve işçilerin şirkete katılmaları"dır ${ }^{51}$. Adıgüzel, halka arzda rüçhan hakkının sınırlandırılması ve kaldırılmasının mecburi olduğunu ileri sürmektedir ${ }^{52}$. Eğer tüm pay sahipleri rüçhan hakkını kullanırsa halka arzdan bahsedilemeyecektir ${ }^{53}$. Ancak rüçhan hakk1 nitelik olarak bir "hak" olduğundan bunun kullanılması zorunlu değildir ${ }^{54}$. Bu nedenle pay sahiplerinin kullanmadığı rüçhan hakkı kapsamındaki payların halka arz edilmesi mümkündür. Bunun haricinde rüçhan hakkının tamamının kullanılması fiilen mümkün olmadığı bir miktarda sermaye artırımı yapılabilir. Şirket bununla hem mevcut hem de halka arz sonucunda müstakbel pay sahiplerinden finansal kaynak sağlamayı hedefleyebilir. Yapılan bu açıklamalar 1şığında kanaatimizce halka arz için rüçhan hakkının sınırlandırılması ve kaldırılması şart değildir.

Şarta bağlı sermaye artırımı (Bedingte Kapitalerhöhung) ile pay sahibi sıfatı verilmesi, rüçhan hakkının sınırlandırılması ve kaldırılması "haklı sebep" olarak sayılmaktadır. Hatta kanun koyucu, TTK m. 465/1-d uyarınca esas sözleşmede "Mevcut pay sahiplerinin rüçhan haklarının kaldırılmış bulunduğunu ve bunun miktarını" hükme bağlanabileceğini dahi öngörmüştür.

Sermaye Piyasası Kurulu'nun hazırladığı Borçlanma Araçları Tebliği (VII-128.8) (BAT) m. 17/6' da belirtildiği üzere paya dönüştürülebilir tahviller aracılığıyla pay sahibi sıfatının kazanılması hakkının kazanılması

51 İşçilerin şirkette pay sahibi olması mevzuunda, doktrinde haklı olarak ilgili anonim şirket ve bunun dahil olduğu şirketler topluluğundan (ana veya yavru şirketten) birinden pay iktisabının da aynı kapsamda olduğu savunulmaktadır (Adıgüzel, s. 16).

52 Adigüzel, s. 15.

53 Sermaye piyasası araçlarının satın alınması için her türlü yoldan yapılan genel bir çağrıya ve bu çağrı devamında gerçekleștirilen satışa "halka arz" denir [6362 sayılı Sermaye Piyasası Kanunu (SPK) m. 3/1-g (RG, T. 06.12.2012, S. 28513)].

54 Bu konu hakkında bkz. Aytaç, s. 307; Şener, s. 587; Sevgi Epçeli, “Türk Ticaret Kanunu Tasarısı' nın Yeni Pay Alma Hakkı ile İlgili Olarak Getirdiği Düzenleme, Eleştiriler ve Öneriler”, 2010, 84(6), İstanbul Barosu Dergisi, s. 3596 vd. 
için rüçhan hakkının sınırlandırılması veya kaldırılması söz konusu olabilir ${ }^{55}$. Başka bir ifadeyle paya dönüştürülebilir tahvil sayesinde pay sahibi sıfatının kazanılması, rüçhan hakkının sınırlandırılması veya kaldırılması için "haklı sebep" sayılabilir. Halka açık anonim şirketlerin paya dönüştürülebilir tahvil ile dönüştürülmek üzere ihraç ettikleri ve artırılacak sermayelerini temsil eden payları, TTK m. 461 ile ortaklara tanınan yeni pay alma hakkı da dahil olmak üzere, her türlü önceliklerden öne alınarak paya dönüştürülebilir tahvil sahiplerine tahsis olunur (BAT m. VII-128.8).

Sermaye Piyasası Kurulu'nun hazırladığ 1 Varantlar ve Yatırım Kuruluşu Sertifikaları Tebliği (VII-128.3) (VYKST) yer alan ortaklık varantlarının ${ }^{56}$ kullanımı suretiyle pay ile uzlaşı sağlanırsa ilgililere pay sahibi sıfatı verilecektir ${ }^{57}$ (VYKST m. 17/1-b). Ortaklık varantlarının kullanımı ile pay sahipliği kazanımı, rüçhan hakkının sınırlandırılması ve kaldırılması için "hakl1 sebep" niteliğindedir. Nitekim VYKST m. 22/1'de bu husus açıç̧a belirtilmiştir. İhraççının kendi payları üzerine yazılı olan ortaklık varantlarının kullanım hakkı kapsamında ihraç edilecek ve ihraççının artırılacak sermayesini temsil eden payları TTK m. 461 ortaklara tanınan yeni pay alma hakkı da dahil olmak üzere, her türlü önceliklerden öne alınarak ortaklık varantı sahiplerine tahsis olunur (VYKST m. 22/1).

\section{Haklı Sebebin Sınırları}

Anonim şirkette rüçhan hakkını sınırlandıran ve kaldıran sebepler için önemli sınırlar çizilmiştir. Bunlara uyulmak suretiyle bahsedilen sınırlandırma veya kaldırma kararı alınabilir. Bu sınırların temeli, TMK m. 2/1'de yer alan dürüstlük kuralıdır. Aşağıda bunlardan en önemlileri incelenmeye çalışılacaktır. Ancak unutulmamalıdır ki incelenecek olan sınırlar haricinde bir durum söz konusu olursa TMK m. 2/1'e başvurulabilir ${ }^{58}$.

55 RG, T. 07.06.2013, S. 28670.

56 Ortaklık varantı; sahibine, vade tarihine kadar ya da vade tarihinde payları borsada işlem gören veya görecek olan kayıtlı sermaye sistemine tabi ihraççı paylarına veyahut payları borsada işlem gören herhangi bir ortaklı̆̆ın paylarına ilişkin olarak bu 17 nci maddede belirlenen uzlaşı yöntemlerinden birini talep etme hakkı veren ve ihraççılarca ilgili sermaye piyasası aracının halka arzı sırasında ihraç edilen sermaye piyasası aracını ifade eder (VYKST m. 3/1-1).

57 RG, T. 10.09.2013, S. 28761.

58 Göksoy, objektif bir neden olmaksızın rüçhan hakkının kaldırılması ve sermaye artırımından pay alamayan pay sahiplerinin önemli bir zarara uğraması neticesinde TMK m. 2/2'de yer alan "hakkın kötüye kullanılması"nın gündeme geleceği fikrindedir (Göksoy, s. 398). Kanaatimizce yazarın belirttiği durumda, bir hakkın ihlali söz konusu olmakla birlikte, 
Geçerli ekonomik kaygılara dayanarak şirket menfaatini veya tüm pay sahiplerinin haklarıyla gerekçelendirilemeyen ya da makul bir amaca hizmet etmeyen rüçhan hakkının sınırlandırılması ve kaldırılması kararları haklı sebep sayılmamaktadır ${ }^{59}$.

\section{A. Eşitlik İlkesi}

Anonim şirkette pay sahiplerinin rüçhan hakkının sınırlandırılması ve kaldırılmasında eşitlik ilkesine uyulması zorunludur. Böylece aynı şartlarda olan pay sahiplerinin rüçhan hakkının sınırlandırılması ve kaldırılması konusunda eşit işleme tâbi tutulması sağlanacaktır ${ }^{60}$.

Anonim şirketler hukukunda eşit işlem ilkesi (Gleichbehandlungsgrundsatz), tüm pay sahiplerinin aynı muameleye tabi tutulması, başka bir ifadeyle bunlar arasında hiçbir hal ve şartta ayrımcılık yapılmaması anlamına gelmemektedir ${ }^{61}$. Zira bahsedilen konuda mutlak değil, nispi eşitlik ${ }^{62}$ kabul edilmiştir ${ }^{63}$. Bu durum, TTK m. 357'deki "Pay sahipleri eşit şartlarda eşit işleme tabi tutulur." hükümde açıkça ifade edilmiştir. Dolayısıyla pay sahipleri arasındaki fark, rüçhan hakkının sınırlandırılması veya kaldırılması konusunda yapılacak ayrımda başlıca ilişki ölçütleri uygunsa eşit işlem ilkesine aykırılıktan bahsedilemeyecektir ${ }^{64}$. Nitekim Yargıtay, bir

TMK m. 2/2'nin gündeme gelmemektedir. Zira hakkın kötüye kullanımı için evvela ortada hukuk düzenince verilen bir hakkın olması ve bunun dürüstlük kuralına aykırı kullanılması, neticede de zarar veya zarar görme tehlikesinin ortaya çıkması gerekir. Dolayısıyla burada TMK m. 2/2'den bahsedebilmek için pay sahibinin rüçhan hakkını, TMK m. 2/1'ye aykırı kullanması şarttır. Yazarın belirttiği durumda rüçhan hakkı kaldırıldığından bunun kötüye kullanımı söz konusu olamayacaktır. Bu nedenle de kanaatimizce, rüçhan hakkının kaldırılmasında TMK m. 2/2'den bahsedilmesine imkân yoktur.

59 Lambert/ Dieter, OR Art. 652b, Nr. 9.

6011 HD., T. 6.10.1997, E. 1997/5583, K. 1997/6609 (http://www.kazanci.com/kho2/ibb/ files/11hd-1997-5583.htm, Erişim Tarihi: 9.11.2020).

${ }^{61}$ Eşit işlem ilkesi, TTK m. 357'de ilk kez kanunda düzenlenmiștir. Bu ilke, TTK'dan önceki dönemde Yargıtay'ın yerleşik kararlarıyla kabul edilmişti. Bu ilke ayrıca Avrupa Ekonomik Topluluğu'nun ticaret şirketlerine ilişkin, sermayeyi konu alan, 77/91 say1l İkinci Yönergesinin 42'nci maddesinde öngörülmüştür (TTK m. 357 gerekçe).

62 Eşitlik ilkesinin derece olarak anlamları (biçimsel, sayısal-mutlak ve nispi eşitlik) hakkında ayrıntılı bilgi için bkz. Yıldız, Eşit İşlem, s. 31-38.

63 Lambert/ Dieter, OR Art. 652b, Nr. 6; Cafer Eminoğlu, "Anonim Şirket Pay Sahipleri Açısından Eşit Şartlarda Eşit İşlem İlkesi”, 2015, 1(1), Ticaret ve Fikri Mülkiyet Hukuku Dergisi, s. 80; Sickinger/ Küthe/ Schuppen/ Schaub, Mah AktR § 33 Rn. 98.

${ }^{64}$ Sickinger/ Küthe/ Schuppen/ Schaub, Mah AktR § 33 Rn. 98; Yıldız, Eşit İşlem, s. 75; Göksoy, s. 402-403; Eminoğlu, s. 83. 
uyuşmazlıkta haklı sebep yokken pay sahiplerinden sadece birinin rüçhan hakkının kaldırılmasını eşitlik ilkesine aykırı olduğuna hükmetmiştir. Yüksek mahkemenin ifadesiyle; "diğer tüm ortaklara eşit oranda sermaye arttırımına iştirak hakkı tanınırken haklı bir gerekçe sunulmaksızın davacı ortă̆ın sermaye arttırımına iştirakının sağlanmamış olduğu, rüçhan hakkının kullandırlmadı̆̆g, bu haliyle alınan kararın herş̧eyden önce dürüstlük ve eşitlik ilkelerine aykırı olduğu anlaşılmıştır. "65.

TTK m. 461/2 gereğince rüçhan hakkının sınırlandırılması ve kaldırılmas1 için nispi eşitliğe uyulması gerekir. Zira rüçhan hakkının sınırlandırılması ve kaldırılmasıyla, hiç kimse haklı görülmeyecek şekilde yararlandırılamaz veya kayba uğratılamaz ${ }^{66}$ (TTK m. 461/2-c. 2). Eğer pay sahiplerinden bazılarının rüçhan hakk1 konusundaki kısıtlamalara tabi olmayacağı kabul edilmişse bunun "haklı görülmesi" şarttır. Bununla birlikte TTK m. 461/2-c. 2 hükmü bazı pay sahiplerinin aleyhine yapılan grup içi yapısal değişikliklerin ve pay oranlarının sulandırılmasını önleyici niteliktedir. Böylece çoğunluk pay sahiplerinin gücü "haklılık" ile sınırlandırılmıştır ${ }^{67}$. Örneğin azınlığın kanunda yer alan "azınlık hakları" korumasından mahrum bırakılması için çoğunluk, rüçhan hakkının sınırlandırılması veya kaldırılmasını sadece bu pay grubu için genel kurulda kabul ederse eşitlik ilkesi ihlal edilmiş olacaktır ${ }^{68}$. Dolayısıyla bu genel kurul kararının iptal edilmesi mümkündür.

Anonim şirketlerde rüçhan hakkı sınırlandırılması veya kaldırılmasında haklı sebebin sınırı olan eşitlik ilkesinde pay sahipleri arasındaki durum incelenmelidir. Bu incelemede odaklanan nokta ise pay miktarlarıdır. Sonuç olarak bahsedilen kısıtlamanın tüm pay sahipleri açısından adil olup olmadığı ile ilgili yapılan denetim, eşitlik ilkesiyle alakalıdır ${ }^{69}$. Eğer eşit işlem ilkesine uygunsa pay sahiplerinden sadece bazılarının rüçhan hakkının sınırlandırılması veya kaldırılması dahi mümkün olacaktır ${ }^{70}$.

Sermaye artırımında rüçhan hakkı sınırlandırılması veya kaldırılması

\footnotetext{
6511 HD., T. 7.5.2019, E. 2017/4590, K. 2019/3495 (http://www.kazanci.com/kho2/ibb/ files/11hd-2017-4590.htm, Erişim Tarihi: 9.11.2020).

66 Bu konuda ayrica bkz. Lambert/ Dieter, OR Art. 652b, Nr. 6 vd.

${ }_{67}$ TTK m. 461/2 gerekçe; Cramer, OR Art. 652b, Nr. 25.

68 Bühler, s. 117-118.

69 Cramer, OR Art. 652b, Nr. 52.

70 Schürnbrand/ Goette/ Habersack/ Kalss, AktG § 186, Rn. 141.
} 
gerekli ve orantılı olsa bile eşit işlem ilkesine aykırı nitelikte olmamalıdır ${ }^{71}$. Aksi halde bahsedilen nitelikteki bir (genel kurul veya yönetim kurulunun aldığı) kararın iptali mümkündür. Ayrıca bunun yönetim kurulu kararı olması halinde, yönetim kurulu üyelerin sorumluluğu da söz konusu olabilir ${ }^{72}$.

\section{B. Gerekli Olması}

Anonim şirketlerde rüçhan hakkı sınırlandırılacak ya da kaldırılacaksa bunun gerçekten de gerekli olması şarttır ${ }^{73}$. Bu anlamda gereklilik ilkesine uygun bir işlem tesis edilmesi zorunludur ${ }^{74}$. Aksi takdirde organların taraflı veya keyfi karar ve uygulamaları sonucu rüçhan hakkının kısmen ya da tamamen kullandırılmaması söz konusu olur ki bu tamamen hukuka aykırıdır. Örneğin sermaye artırımıyla hedeflenen husus, rüçhan hakkının sınırlandırılmadan veya kaldırılmadan da elde edilebilecekse rüçhan hakkının kısıtlanması işleminde gereklilik şartının sağlanmadığ 1 kabul edilmelidir ${ }^{75}$.

Anonim şirketlerde gereklilik ilkesi uyarınca, gösterilen haklı sebebin şirketin menfaati, varlığ 1 ve devamı için elzem ve objektif olarak geçerli olması şarttır ${ }^{76}$. Bu gereklilik, amaç77 yönünden yapılan bir denetimle anlaşılabilir ${ }^{78}$. Bu anlamda şirket için tek veya en iyi ihtimal rüçhan hakkının sınırlandırılması veya kaldırılması ise bunun gerekli olduğu kabul edilecektir. Başka bir ifadeyle anonim şirketin menfaati gereği, pay sahiplerinin rüçhan hakkını sınırlandırmak ya da kaldırmaktan başka çare yoksa yahut da imkân dahilindeki en iyi seçenekse buna başvurulabilirr ${ }^{79}$. Netice olarak rüçhan hakkının sınırlandırılması ve kaldırılması her zaman "ultima ratio"

71 Cramer, OR Art. 652b, Nr. 52; Sickinger/ Küthe/ Schuppen/ Schaub, Mah AktR § 33 Rn. 98.

72 Yildiz, s. 291-292.

73 Koch/ Hüffer, AktG § 186, Rn. 27; Bühler, s. 117; Akın, s. 30; Göksoy, s. 401; Yıldız, s. 287.

74 Cramer, rüçhan hakkının sınırlandırılması ve kaldırılması için gereklilik incelemesini, "orantılılık" başlığı altında yapılması kanaatindedir (Cramer, OR Art. 652b, Nr. 36-40).

75 Apfelbacher/ Niggemann/ Holters, AktG § 186, Rn. 63.

76 Yıldız, Eşit İ̧̧lem, s. 155; Hermanns/ Henssler/ Strohn, AktG § 186, Rn. 12; Adıgüzel, s. 10.

77 Belirtmek gerekirse; rüçhan hakkının sınırlandırılması ve kaldırılması ile güdülen amaca ulaşılamaması daha sonradan alınan kısıtlama kararının geçersizliğine sebep olmayacaktır (Schürnbrand/ Goette/ Habersack/ Kalss, AktG § 186, Rn. 146).

78 Y. 11.HD., T. 28.10.2004, E. 2003/13782, K. 2004/10454.

79 Schürnbrand/ Goette/ Habersack/ Kalss, AktG § 186, Rn. 102; Servatius/ Spindler/ Stilz, AktG § 186, Rn. 48; Bühler, s. 118; Adıüzel, s. 10; Cramer, OR Art. 652b, Nr. 39; Rieder/ Holzmann/ Grigoleit, AktG § 186, Rn. 54; Apfelbacher/ Niggemann/ Holters, AktG § 186, Rn. 63. 
sayılmamaktadir ${ }^{80}$.

Rüçhan hakkının sınırlandırılması ve kaldırılması için gösterilen haklı sebebin gereklilik sınırına göre; bu kısıtlama, hedefe ulaşmak için en hafif ${ }^{81}$ ve en uygun araç olmalıdır ${ }^{82}$. Bu anlamda gereklilik ile orantıl11ık ilkelerinin haklı sebep yönünden yapılan değerlendirmede çok sıkı ilişkiye sahip olduğu söylenebilir ${ }^{83}$.

\section{Orantılı Olması}

Anonim şirketlerde rüçhan hakk1 sınırlandırılması ve kaldırılmasının orantılı yapılması şarttır ${ }^{84}$. Bu şart, orantılılık ilkesinin (Verhältnismäßigkeitsgrundsatz) gereğidir. Dolayısıyla söz edilen kararın alınması, şirketin menfaatine ve gereklilik ilkesine uygun olsa bile orantılı olmak zorundadır ${ }^{85}$. Amaç ve araç orantısının sağlanması halinde rüçhan hakkının sınırlandırılmasına ve kaldırılmasına karar verilebilir ${ }^{86}$.

Rüçhan hakkının sınırlandırılması ve kaldırılmasında çoğunluğun suiistimalinin önüne geçilmesi açısından orantılık şartı, merkezi öneme sahiptir. $\mathrm{Bu}$ anlamda rüçhan hakkı konusunda yapılacak kısıtlama için şu soruya olumlu cevap verilmesi şarttır; "Şirketin çıkarlarına uygun olan rüçhan hakkının sinırlandırılmasının veya kaldırılmasının mevcut pay sahiplerinin haklarının sınırlandırılması ile orantılı mıdır?"87.

Yukarıda "anonim şirketin menfaati" konusunda bahsedildiği üzere; rüçhan hakkına yapılacak kısıtlama ne kadar ciddi olursa, bu konudaki şirket menfaati de o derece önemli olmalıdır. Görüldüğ̈ü üzere; bu değerlendirme,

s0 Schürnbrand/ Goette/ Habersack/ Kalss, AktG $§ 186$, Rn. 102; Rieder/ Holzmann/ Grigoleit, AktG $§ 186$, Rn. 54.

81 BGer, 4C.242/2001, Urteil vom 5. März 2003, E. 4.2 (https://www.bger.ch/ext/eurospider/ live/de/php/aza/http/index.php?highlight_docid=aza\%3A\%2F\%2F05-03-2003-4C-2422001\&lang=de\&type=show_document\&zoom=YES\&, Erişim Tarihi: 7.11.2020).

82 Koch/ Hüffer, AktG § 186, Rn. 27.

83 Cramer, OR Art. 652b, Nr. 38.

84 Hermanns/ Henssler/ Strohn, AktG § 186, Rn. 12; Rieder/ Holzmann/ Grigoleit, AktG $§ 186$, Rn. 52; Koch/ Hüffer, AktG § 186, Rn. 28.

85 Lambert/ Dieter, OR Art. 652b, Nr. 10; Cramer, OR Art. 652b, Nr. 1; Adigüzel, s. 13.

86 Schürnbrand/ Goette/ Habersack/ Kalss, AktG § 186, Rn. 103; Rieder/ Holzmann/ Grigoleit, AktG $\S 186$, Rn. 54.

87 Servatius/ Spindler/ Stilz, AktG $§ 186$, Rn. 49; Apfelbacher/ Niggemann/ Holters, AktG $\S$ 186, Rn. 64. 
bir yönüyle de haklı sebebin orantılı olması ile ilgilidir ${ }^{88}$.

Cramer'e göre rüçhan hakkının sınırlandırılması ve kaldırılmasının haklı sebebi incelenirken orantıl1lık konusunda, üç kriter yönünden değerlendirme yapılmalıdır. Bu kriterler; uygunluk, gereklilik ve rasyonelliktir ${ }^{89}$. Ancak kanaatimizce gereklilik ilkesinin önemi ve bunun orantıl1lık ile arasındaki farklarından dolayı söz edilen ilkenin ayrı bir başlık altında değerlendirilmesi gerekir. Cramer' in uygunluk kriterine göre, gösterilen sebebin genel kurul veya yönetim kurulunun amacı arasında bir uygunluğun olması gerekir. Örneğin şirketin birleşmesi haklı sebep olarak gösterilip rüçhan hakkı sınırlandırılmış veya kaldırılmışsa birleşme amacının devamlılığ 1 şarttır ${ }^{90}$.

Orantılı1ık ilkesi gereği olarak, rüçhan hakkının sınırlandırılması ve kaldırılması kararı şirket menfaatine olmakla birlikte pay sahiplerinden birine veya bazılarına zarar verecekse arzu edilen amaç için diğer ihtimaller değerlendirilmelidir. $\mathrm{Bu}$ ihtimaller, eğer daha az zararlı veyahut tamamen zararsızsa orantıl11ık ilkesine uygun olan, ikinci seçenektir ${ }^{91}$. Örneğin rüçhan hakkının sadece \%10'luk kısmı sınırlandırılmış olmasına rağmen somut olayda öne sürülen sebep için sadece $\% 5$ 'lik oran yeterliyse buna uyulmas1 zorunludur. Zira rüçhan hakkının sadece $\% 5^{\prime}$ lik sınırlandırılması yeterliyken bundan daha fazla bir orana karar verilmesi orantılılık ilkesine aykırıdır. Benzer şekilde, rüçhan hakkının sınırlandırılması ile karar için belirtilen sebebe ulaşmak mümkünken bunun kaldırılması orantılılık ilkesine aykırıdır. Yahut da borç alma imkânı varken bunun yerine sermaye artırımı ile istenilen finansal desteğe kavuşulacaksa burada rüçhan hakkının sınırlandırılması ve kaldırılması orant1l11ık ilkesine uygun değildir ${ }^{92}$.

Yukarıda belirtildiği üzere rüçhan hakkının kısıtlanması ile şirket menfaatinin derecesi doğru orantıdadır. Bu durumda çıkar çatışmaları, oy ve güç kaybı gibi hususlar birbiriyle orantılanıp rüçhan hakk1 konusunda karar verilir. Bu durumda başka çözümler daha uygunsa rüçhan hakkının sınırlandırılması ve kaldırılmasına karar verilemez ${ }^{93}$.

88 Hermanns/ Henssler/ Strohn, AktG § 186, Rn. 12; Koch/ Hüffer, AktG § 186, Rn. 28; Rieder/ Holzmann/ Grigoleit, AktG § 186, Rn. 54; Sickinger/ Küthe/ Schuppen/ Schaub, Mah AktR $\S 33$ Rn. 100.

89 Cramer, OR Art. 652b, Nr. 36.

90 Cramer, OR Art. 652b, Nr. 37.

91 Rieder/ Holzmann/ Grigoleit, AktG § 186, Rn. 54; Y1ldız, s. 293; Böckli, Nr. 256.

92 Servatius/ Spindler/ Stilz, AktG § 186, Rn. 48; Göksoy, s. 408; Adıgüzel, s. 14.

93 Rieder/ Holzmann/ Grigoleit, AktG § 186, Rn. 54; Servatius/ Spindler/ Stilz, AktG § 186, Rn. 49. 


\section{SONUÇ}

1. Anonim şirket menfaati, sosyal ya da ekonomik gerekçelerle; dürüstlük kuralına, gerekli, orantılı ve eşit işlem ilkesine uygun olarak rüçhan hakkının sınırlandırılmasını ya da kaldırılmasını haklı kılan objektif nedenlere kanaatimizce haklı sebep denir.

2. Anonim şirkette tüm pay sahipleri, rüçhan hakkını kullanırsa halka arzdan bahsedilemeyecektir. Ancak rüçhan hakkı nitelik olarak bir "hak" olduğundan bunun kullanılması zorunlu değildir. Bu nedenle pay sahiplerinin kullanmadığı rüçhan hakkı kapsamındaki payların halka arz edilmesi mümkündür. Bunun haricinde rüçhan hakkının tamamının kullanılması fiilen mümkün olmadığı bir miktarda sermaye artırımı yapılabilir. Şirket bununla hem mevcut hem de halka arz sonucunda müstakbel pay sahiplerinden finansal kaynak sağlamayı hedefleyebilir. Yapılan bu açıklamalar ışığında kanaatimizce halka arz için rüçhan hakkının sınırlandırılması ve kaldırılması şart değildir.

3. Hakkın kötüye kullanımı için evvela ortada hukuk düzenince verilen bir hakkın olması ve bunun dürüstlük kuralına aykırı kullanılması, neticede de zarar veya zarar görme tehlikesinin ortaya çıkması gerekir. Dolayısıyla rüçhan hakkının kötüye kullanımından bahsedebilmek için pay sahibinin rüçhan hakkını, TMK m. 2/1'ye aykırı kullanması şartır. Ancak rüçhan hakkının kaldırılmasında, rüçhan hakkının kötüye kullanılmasından kanaatimizce mümkün değildir. Zira rüçhan hakkı kaldırıldığından bunun kötüye kullanımı söz konusu olamayacaktır. $\mathrm{Bu}$ nedenle de kanaatimizce, rüçhan hakkının kaldırılmasında TMK m. 2/2'den bahsedilmesine imkân yoktur.

\section{KAYNAKÇA}

Adıgüzel B, “Anonim Şirketlerde Rüçhan Hakkının Sınırlanması veya Kaldırılması", 2014, 18(1), Gazi Üniversitesi Hukuk Fakültesi Dergisi, s. $1-48$.

Akın Y M, "Kayıtlı Sermayede Rüçhan Hakkının Sınırlandırılması veya İlgilinin Bu Hakkı Kullanımdan Yoksun Bırakılmasındaki Kıstaslar", 1995, Prof. Dr. Reha Poroy'a Armağan, İ̈̈HF s. 7-37. 
Akünal T, “Anonim Ortaklıkta Pay Sahiplerinin Yeni Pay Alma Hakkı”, 1969, 3(5), Mukayeseli Hukuk Araştırmaları Dergisi, s. 257-278.

Apfelbacher G/ Niggemann G, Aktiengesetz Kommentar (Hrsg. Holters W), 3. Auflage, CH Beck Verlag, 2017.

Aytaç Z, "Anonim Ortaklıklarda Rüçhan Hakkı", 1985, Ticaret Hukuku ve Yargitay Kararları Sempozyumu II, s. 297-340.

Azarkan N, Die Kapitalerhöhung in der AG nach deutschem und türkischem Recht, Dis., Peter Lang, 2008.

Bahtiyar M, Anonim Ortaklıkta Kayıtlı Sermaye Sistemi ve Sermaye Artırımı, Beta Basım, 1996.

Bilgili F/ Demirkapı E, Şirketler Hukuku, 3. Baskı, Dora, 2013.

Böckli P, Schweizer Aktienrecht mit Fusionsgesetz, Börsengesellschaftsrecht, Konzernrecht, Corporate Governance, Recht der Revisionsstelle und der Abschlussprüfung in neuer Fassung - unter Berücksichtigung der angelaufenen Revision des Aktien - und Rechnungslegungsrechts, 4. Auflage, Schulthess, 2009.

Bühler R, Kapitalerhöhung aus Eigenkapital nach Art. 652d OR, Dis., Universität St. Gallen, 2019.

Cenkci E, "Kayıtlı Sermaye Sisteminde Yeni Pay Alma (Rüçhan) Hakkının Sınırlandırılması Bağlamında Genel Kurulun Yetkileri -Alman ve İsviçre Hukuku ile Karş1laştırmalı", 2016, 122, Türkiye Barolar Birliği Dergisi, s. 315-336.

Cramer C, Allgemeine Bestimmungen, Art. 620-659b OR Die Aktiengesellschaft (Hrsg. Handschin L), 2. Auflage, Schulthess, 2016.

Eminoğlu C, "Anonim Şirket Pay Sahipleri Açısından Eşit Şartlarda Eşit İşlem İlkesi”, 2015, 1(1), Ticaret ve Fikri Mülkiyet Hukuku Dergisi, s. 79-88.

Epçeli S, “Türk Ticaret Kanunu Tasarısı' nın Yeni Pay Alma Hakkı ile İlgili Olarak Getirdiği Düzenleme, Eleştiriler ve Öneriler”, 2010, 84(6), İstanbul Barosu Dergisi, s. 3589-3625.

Göksoy C Y, "Anonim Ortaklıkta Pay Sahibinin Yeni Pay Alma Hakkının Kaldırılması", 2003, Bilgi Toplumunda Hukuk, Ünal Tekinalp'e Armağan, s. 363-440. 
Grechenig K, Bezugsrechtsausschluss und Ausgabepreis nach Art. 652b OR, Schweizerische Zeitschrift für Wirtschafts- und Finanzmarktrecht, SZW, Schulthess, 2008.

Hermanns M, Gesellschaftsrecht (Hrsg. Henssler M/ Strohn L), 4. Auflage, 2019.

Koch J/ Hüffer U, Aktiengesetz, 14. Auflage, CH Beck Verlag, 2020.

KorkutÖ, “Anonim Şirketlerde ŞirketMenfaatiKavramının Somutlaştırılması”, 2007, 11(2), Çukurova Üniversitesi İktisadi ve İdari Bilimler Dergisi, s. $1-9$.

Krämer, H J, Das Unternehmensinteresse als Verhaltensmaxime der Leitungsorgane einer Aktiengesellschaft im Rahmen der Organhaftungin Abgrenzung zum Gesellschaftsinteresse und unter Berücksichtigung US- amerikanischer Rechtsprechung und Literatür, Tenea, Bayreuth, 2002.

Müller W, Personengesellschaften und Aktiengesellschaft Art. 530-771 OR (Hrsg. Roberto V/ Trueb H R), 2. Auflage, Schulthess, 2012.

Lambert C/ Dieter G, OR Kommentar Schweizerisches Obligationenrecht (Hrsg. Kostkiewicz J K/ Wolf S/ Amstutz M/ Fankhauser R), 3. Auflage, Orell Füssli Verlag, 2016.

Ott E, Das Bezugsrecht der Aktionäre, Diss., 1962.

Pulaşlı H, Şirketler Hukuku Genel Esaslar, 4. Baskı, Adalet Yayınevi, 2016.

Rieder M S/ Holzmann D, Aktiengesetz Kommentar (Hrsg. Grigoleit H C), CH Beck Verlag, 2013.

Schaller P/ Kessler M A, Aktienrecht Kommentar Aktiengesellschaft, Rechnungslegungsrecht, VegüV, GeBüV, VASR (Hrsg. Wimbmer J K) - Zürich, 2016.

Schürnbrand J, Münchener Kommentar zum AktG (Hrsg. Göette W/ Habersack M/ Kalss S), Bd. 4, 4. Auflage, CH Beck Verlag, 2018.

Servatius W, Kommentar zum Aktiengesetz (Hrsg. Spindler G/ Stilz E), Bd. 2, 4. Auflage, 2019.

Sickinger M/ Küthe T, Münchener Anwaltshandbuch Aktienrecht (Hrsg. 
Anonim Şirket Hukukunda Rüçhan Hakkının Sınırlandırılması ve Kaldırılmasında...

Schüppen M/ Schaüb B), 3. Auflage, CH Beck Verlag, 2018.

Şener O H, Teorik ve Uygulamalı Ortaklıklar Hukuku, 3. Baskı, Seçkin Yayıncilik, 2017.

Üçışık G/ Çelik A, Anonim Ortaklıklar Hukuku, C. I, Adalet Yayınevi, 2013.

Yıldız Ş, “6102 sayılı Türk Ticaret Kanunu'nda Rüçhan Hakkı Konusunda Getirilen Değişiklikler”, 2012, 18(2), 6102 Sayılı Türk Ticaret Kanunu'nu Beklerken Sempozyumu, Marmara Üniversitesi Hukuk Fakültesi Hukuk Araştırmaları Dergisi, s. 809-818 (anılış: Yıldız, Değişiklikler).

Yıldız Ş, Anonim Ortaklıkta Yeni Pay Alma Hakkı, Beta Basım, 1996.

Yıldız Ş, Anonim Ortaklıkta Pay Sahipleri Açısından Eşit İşlem İlkesi, Seçkin Yayıncılık, 2004 (anılış: Yıldız, Eşit İşlem). 